\title{
Introduction to World Nutrition, Issue One for 2018
}

As usual, this issue begins with a Good Question from our Deputy Editor, George Kent. Illustrating with an example from infant feeding research and how governments interpret and present its implications, he asks who is responsible for correcting misinterpretations?

Some nutrition data are time-bound. Except in such cases, for example where analytical methods have changed, I don't see any justification in asking authors to cite only papers published after say 2000, which some journals do. In the case of a research paper in this issue by Shrimpton and Marinho, based on work done nearly 40 years ago, the fact that a sample of urban Amazonian women had nutritional deficiencies at that time is only of historical interest, say to those who may want a baseline to compare to. But the results of a placebo controlled randomized trial do not lose their significance. This paper provides the first published evidence that zinc supplementation alone increases breast milk vitamin A in apparently zinc deficient mothers.

Our second research article, by Rahman et al., examines whether taste testing of water is accurate enough to use in assessing whether it is high in iron and thus of potential value in preventing iron deficiency. Next, a literature review by Vandenplas explains some of the harm that antibiotic treatment, especially the use of broad spectrum antibiotics, can do in infants, some of which is related to growth and to the microbiome.

In a further reference to ancient history, within the Swedish delegation on the floor of the first International Conference on Nutrition in 1992, I suggested that the conference adopt goals and targets, one of which was to end famine within a decade. The fact that eradicating famine was feasible was not understood in the following debate and the goal was changed to relate to malnutrition generally.

But actually, we came close to ending famine anyway. However, now, to paraphrase a letter I received from our next author, Alex de Waal, barbarians occupying the highest offices in many of our countries have brought famine roaring back as collateral damage or even a tool of war. The points he makes in his riveting commentary in this issue should concern each of us, not just as public health experts, but as human beings. We can-we must-demand that mass starvation be defined as a crime against humanity and be prosecuted accordingly. Thousands, probably millions of lives could be saved already today in Yemen and elsewhere. In this same issue of WN, Regina Keith reviews de Waal's latest book, Mass Starvation: The History and Future of Famine.

Claudio Schuftan's commentary next asks a similar question: What would happen if public health nutritionists really cared more about hunger and malnutrition from a right to nutrition perspective?

As the World Public Health Nutrition Association insists in all contexts, public health must remain independent and free from conflicts of interest. The current dominance of neoliberalism globally has proven its value to corporations and their wealthy owners, stockholders and 
executives. It continues to push the boundaries, as past articles in this journal have indicated is happening in the USA particularly. The clever ways in which corporate interests insert themselves into public health nutrition is illustrated by an excellent article in this issue by Granheim and Lie on the SUN (Scaling Up Nutrition) movement and conflicts of interest in global nutrition governance.

Valerie McClain examines a related issue that gets far too little attention in our field-patents on life. While referring to seeds and other examples, she focuses on the patenting of breast milk components. Much work on such issues, such as the production of insulin using GMO methods, may make us feel exhilarated over what we can achieve. But McClain gives us food for thought — are we giving enough thought to the implications of all this?

Acknowledgements: All images used in WN obtained permission for their use or are available on the internet at no cost. We want to thank the following sources for the images using in this issue:

Human Rights Watch

Ted Greiner

Editor-in-Chief 